\title{
Información del PH \\ Informe BIC sobre la Cuenca Minera de Riotinto para su declaración como Sitio Histórico
}

\author{
Emilio M. Romero Macías ${ }^{1}>$ Esteban Ruiz Ballesteros $^{2}>$ Juan M. Pérez López $^{3}>$ Elena Aguilera Collado $^{4}>$
}

Rafael Aguilera Carrasco ${ }^{5}$

\section{Resumen}

En el año 2001, la Comisión de Patrimonio de la Junta de Andalucia, a través de la Delegación Provincial de Cultura de Huelva, acordó incoar expediente BIC a la Cuenca Minera de Riotinto para su declaración como Sitio Histórico, con la finalidad de proteger los elementos representativos de las diversas etapas históricas que han conformado a este territorio desde los tiempos prehistóricos hasta la actualidad, teniendo en cuenta el innegable valor que ha tenido la actividad minera como precursora del desarrollo económico e industrial en la provincia de Huelva.

\section{Palabras clave}

\section{Cuenca Minera de Riotinto}

Huelva

Bien de Interés Cultural

Sitios Históricos

Bienes inmuebles

Minería

Historia
La Cuenca Minera de Riotinto es uno de esos espacios diferenciados de Andalucia que aún hoy sorprende al visitante por la originalidad de su paisaje, sus formas y el eclecticismo cultural de sus gentes, todo ello fruto de la actuación del hombre sobre el medio y por su acervo cultural e histórico. La Cuenca Minera de Riotinto cuenta con una extensión de aproximadamente $640 \mathrm{~km}^{2}$, lo que supone casi el $6,5 \%$ de la extensión provincial y ocupa una posición de centralidad en el sistema vial de comunicaciones. Desde el punto de vista administrativo la componen siete municipios: Berrocal, El Campillo, Campofrío, La Granada de Riotinto, Minas de Riotinto, Nerva y Zalamea la Real, entre los que se distribuyen sus aproximadamente 20.000 habitantes. A estos 7 municipios pertenecen también 7 pedanías: El Villar, El Pozuelo, El Buitrón, Las Delgadas, Monte Sorromero, Membrillo, Ventas de Arriba y Marigenta.

Desde una perspectiva histórica, la Cuenca Minera está configurada "por y para la mina". No se entiende nuestra historia sin los hechos emanados de ella. Ha sido el referente socio-económico para que los pobladores desde la antigüedad se asentasen en la denominada Faja Piritica del S-W ibérico. Sin la actividad minera nuestra comarca no hubiera tenido el desarrollo económico, que permitió colocar el nombre de "Riotinto" en todos los mercados mundiales de cobre y sobre todo de piritas.

La historia de la Comarca de Río Tinto es singular por muchos y variados condicionantes, pero sobre todo por dos aspectos fundamentales, en primer lugar, como hemos apuntado al inicio, porque siempre ha estado marcada por la existencia y explotación de sus minas y en segundo lugar, porque siempre ha dependido de las civilizaciones o empresas que las explotaron. Estas fueron generando a través de su explotación un patrimonio cultural e histórico, que es el que se pretende poner en valor.

Hasta ahora el patrimonio artístico, sobre todo de civilizaciones antiguas, no plantea duda en su conservación y más o menos toda la sociedad acepta su valor patrimonial y conceptual de un pasado histórico. Pero no es hasta la década de los 50 en el Reino Unido cuando se produce el nacimiento de la arqueología industrial, como respuesta a la necesidad de conservar unos edificios industriales que formaban parte del paisaje, y de un pasado histórico más reciente que explicaba las formas de vida de una sociedad nacida a raíz de la revolución industrial.

Posteriormente, en 1978 en Grangarde (Suecia), se reúne el primer Comité Internacional para la Conservación del Patrimonio Industrial $(\mathrm{TICCIH})$. Son las primeras iniciativas para organizar la protección de los restos industriales. Este organismo incluye dentro de Patrimonio Industrial, los restos físicos del pasado industrial (paisaje, lugares, infraestructuras, edificios, productos y equipamientos industriales); así como aquella documentación producida por la propia industria (archivo, recuerdos personales, memorias, etc.). 


\section{$044-045$ \\ Información del PH}

Informe BIC sobre la

Cuenca Minera de Riotinto

para su declaración como

Sitio Histórico

PH45 - Octubre 2003

El Patrimonio Industrial está constituido por los bienes muebles e inmuebles generados, en el transcurso histórico, por las actividades extractivas y productoras del hombre. Estos bienes patrimoniales se insertan en un paisaje o entorno determinado que también ha de ser objeto de protección debido a que la industria es una consecuencia directa del uso que la sociedad hace del medio natural. La administración no contempla en el enunciado de la ley de patrimonio el concepto de patrimonio industrial, pero es obvio que éste va implícito en el patrimonio etnográfico y en el patrimonio científico-técnico, ambos contemplados en la legislación.

En la Cuenca Minera de Riotinto la actividad minera había ordenado la vida, las costumbres y hasta el sentir de toda una comarca durante toda su historia; por lo que se hace necesario, a
${ }^{1}$ Emilio M. Romero Macias. Doctor en Geología e Ing. Téc. Minas. Universidad de Huelva

${ }^{2}$ Esteban Ruiz Ballesteros. Universidad Pablo de Olavide. Sevilla. Doctor Antropología Social

3 Juan M. Pérez López. Director del Archivo Histórico Minero. Fundación Rio Tinto

${ }^{4}$ Elena Aguilera Collado. Arqueóloga. Delegación Provincial de Cultura de Huelva

${ }^{5}$ Rafael Aguilera Carrasco. Arquitecto

\section{Catálogo de elementos BIC}

1 Dolmen de La Lancha

2 Taller lítico La Chaparrita

3 Necrópolis La Parrita

4 Tres Águilas

5 Marismillas

6 Cerro del Moro

7 Padre Caro

8 Necrópolis Marismilla

9 Planes

10 Tres Cruces

11 Necrópolis Tres Cruces

12 Calzada Tres Cruces

13 Necrópolis Huerta Cana

14 Poblado Corta Lago

15 Necrópolis La Dehesa

16 Corta Dehesa

17 Corta Salomón

18 Peña del Hierro

19 Escorial La Chaparrita

20 Torreta del Campillo

21 Poblado Fuente del Ventoso

22 Necrópolis de Bellavista

23 Asentamiento de Bellavista

24 Chimenea de fundición

25 Fuente El Ventoso

26 Teleras

27 Túnel Sta. María

28 Malacate Peña del Hierro

29 Cementación Planes

30 Cementación Naya

31 Planta muestras San Luis

32 Edificio Casa Palancas

33 Túnel piso 11

34 Almacén Mina

35 Locomotora Clase C $n^{0} 14$
36 Embalse Marismillas

37 Cementerio Bellavista

38 Semáforo FC

39 Farol

40 Puente túnel Naya

41 Palancas de cambios de vías

42 Barrio Bellavista

43 Casa Consejo

44 Estación Peña del Hierro

45 Estación túnel Naya

46 Vagón doble vuelco tipo D2

47 Coche viajeros tipo $\mathrm{B} \mathrm{n}^{0} 2$

48 Bomba Cornish

49 Casa Consistorial Nerva

50 Capilla Bellavista

51 Estación FC Riotinto

52 Convento

53 Fuente de La Reú

54 Club inglés

55 Estación FC Nerva

56 La Factoría

57 Postes señales

58 Semáforo de brazo

59 Pórtico de señales

60 Locomotora grúa

61 Locomotora vapor clase I

62 Corta Atalaya

63 Fundición piritas

64 Chimenea pirita

65 Locomotora vapor clase $\mathrm{K}$

66 Vagón doble vuelco tipo $F$

67 Central térmica

68 Vagón mercancías tipo A

69 Vagón simple vuelco tipo B-2

70 Vagón pasajeros tipo J-2
1. Vista de Teleras

2. Señales ferroviarias en Mina Pueblo

partir de la crisis minera y de la consiguiente pérdida de sus valores intrínsecos, que las instituciones oficiales promuevan y canalicen las acciones socio-culturales en el territorio minero, actuando desde el referente identificador de patrimonio "Cultural", en su acepción más amplia de patrimonio "Histórico", que poseen todos aquellos bienes, indicios o manifestaciones que nos acercan al conocimiento de civilizaciones pasadas.

En la década de los 70, en el momento de las reconversiones, el objetivo prioritario es la conservación y se plantea qué es lo que hay que hacer tanto con el patrimonio como con el excedente humano que generan las áreas en crisis (museos técnicos y cientificos). El Patrimonio Industrial deja de ser una rémora para las administraciones y se convierte en un instrumento de desarrollo 


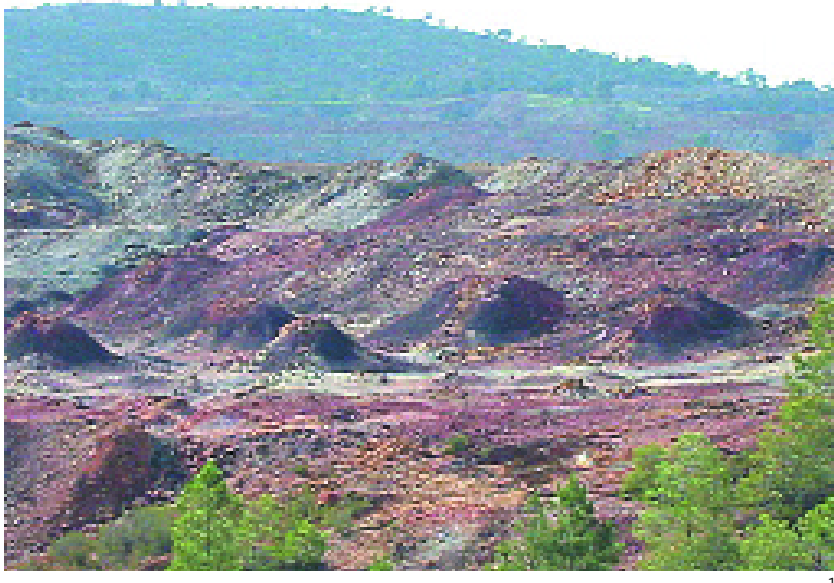

local. Patrimonio "cultural", tanto histórico como industrial, y tanto material como inmaterial; forman el eje central de grandes proyectos turísticos (Parque Minero de Riotinto, Museo del Carbón en Asturias, Museo de la Ciencia y de la Técnica en Cataluña, Museo del Ferrocarril en Gijón, etc.). Como consecuencia se produce la creación de Centros de Interpretación histórica a través de los elementos e instalaciones industriales que analizan y explican la historia social y económica de una determinada región.

\section{Delimitación y justificación de los bienes}

En cuanto a la ubicación de la mayoría de los elementos patrimoniales que van a componer el BIC "Sitio Histórico Cuenca Minera de Riotinto", se localizan en los municipios de Nerva (latitud 37 41' longitud -6 32') y Minas de Riotinto (latitud 37 41' longitud -6 35'). Entre ambos municipios suman una extensión superficial de $78 \mathrm{~km}^{2}$. En cuanto a su justificación hay que tener en cuenta:

I. El artículo 13.27 de la Ley Orgánica 6/1981, de 30 de diciembre, del Estatuto de Autonomía para Andalucía, establece la competencia exclusiva de la Comunidad Autónoma en materia de patrimonio histórico, artístico, monumental, arqueológico y científico y el artículo 6.a) de la Ley 16/1985, de 25 de junio, del Patrimonio Histórico Español, determina que se entenderán como organismos competentes para la ejecución de la Ley los que en cada Comunidad Autónoma tengan a su cargo la protección del patrimonio histórico.

Asimismo, el artículo 2 del Decreto 4/1993, de 26 de enero, por el que se aprueba el Reglamento de Organización Administrativa del Patrimonio Histórico de Andalucía, atribuye a la Consejería de Cultura de la Junta de Andalucía la competencia en la formulación, seguimiento y ejecución de la política andaluza de bienes culturales, referida a la tutela, enriquecimiento y difusión del Patrimonio Histórico Andaluz, siendo, de acuerdo con su artículo 3.3, el titular de la Consejería de Cultura el órgano competente para proponer al Consejo de Gobierno de la Junta de Andalucía la declaración de bienes de interés cultural y competiendo, según el artículo 1.1 del citado Reglamento, a este último dicha declaración.

II. El sitio histórico de Riotinto es uno de los mejores exponentes para comprender y conocer la evolución histórica de las explotaciones mineras a través de distintas sociedades en el suroeste europeo. Este territorio encierra en sí mismo importantes recursos patrimoniales que pueden ser claves para el conocimiento de la diversidad cultural que ha caracterizado a las sucesivas sociedades mineras, desde puntos de vista tan diversos como económico, tecnológico, político, social, comercial y de la interacción entre hombre-medio en cuanto a lo que ha supuesto el aprovechamiento de los recursos mineros en este foco onubense, asi como para entender la trayectoria histórica del propio territorio que hoy conforma la provincia de Huelva.

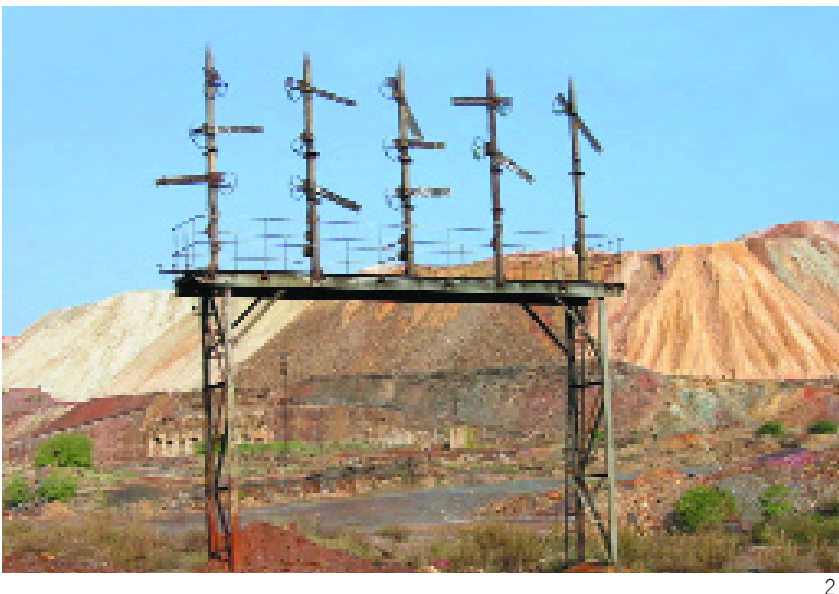

\section{Descripción}

La descripción global de los bienes se realizó en su ficha especifica que permite su plena identificación. No obstante, a continuación destacamos una relación sumaria de los bienes incluidos como objeto de declaración de BIC.

\section{A) Edificios industriales}

Desde su llegada al territorio minero español, la compañía inglesa RTCL empieza la construcción de instalaciones relacionadas con la explotación del cobre. Hoy dia, de los edificios industriales levantados a lo largo de un siglo apenas subsisten algunos, tan sólo los más modernos o aquellos a los que se les encontró una última utilización. Los demás han ido desapareciendo paulatinamente tras haber sido de gran interés en el contexto de una arquitectura que por su singularidad y lo que significó en la revolución industrial de la minería onubense, deberían haberse preservado o al menos estudiado y catalogado antes de ser arrasados.

Desde aquí haremos mención a los más importantes, teniendo en cuenta que únicamente existen los restos e incluso en algunos casos sólo los cimientos de muchos de ellos, pero que no dejan de ser importantes aunque solamente sea tenida en cuenta su mención por la importancia que tuvieron en sus tiempos.

Antes de la llegada de la Riotinto Company Limited ya existían algunas actividades industriales en las minas con una serie de edificios singulares: Fábrica de Sta. Maria, Fábrica de San Luis, Reverbero, Fábrica de La Cerda y Fábrica de Los Planes. Por otra parte, amén de la enorme área de tostación de teleras (calcination ground) que produciría enormes estragos en la flora del lugar y en el ánimo de la población, existían unos estanques de lavado y cementación, que según los estudiosos en el tema pertenecian a las primitivas explotaciones del marqués de Remisa. Junto a ellos, en el sector conocido por La Cerda, existieron unos nuevos estanques ya construidos por los ingleses (new washing and precipitating tanks).

En este mismo contexto se construyó el Almacén Minas hacia el año 1874. Allá por el año 1891 la RTCL construyó en los terrenos de Naya unas cocheras (running sheds) y un complejo de estanques de cementación (precipitation tanks). En esta época ya aparecen los talleres primitivos del pueblo antiguo de La Mina amenazados por las labores de Filón Sur al borde de la corta.

Los primeros datos sobre una fundición se refieren a la ubicada en el paraje de Huerta Romana (Huerta Romana Blast Furnace) en el lugar donde hoy se encuentran los restos de la Central Eléctrica. También en esta época, en los terrenos denominados La Cerda existen ya unas enormes extensiones de estanques de precipitación, así como nuevos estanques de lavados junto a Riotinto Estación. Por último, existe la primitiva fábrica de ácido sulfúrico (demolida y construida en 1930) y junto a ella, camino de Nerva, en el lugar denominado Planes, también existía un com- 


\section{$046-047$ \\ Información del PH}

Informe BIC sobre la

Cuenca Minera de Riotinto

para su declaración como

Sitio Histórico

\section{PH45 - Octubre 2003}

plejo denominado Shulphate of Cooper Works y Planes Precipitating Tanks (un nuevo frente de trabajo de la cementación del cobre). De esta época tan sólo perduran en la actualidad el Almacén Minas y los estanques de Naya.

La primitiva fundición de Huerta Romana funcionó hasta 1900, cuando se construyó la Fundición Bessemer en el lugar de los actuales Talleres Minas, construidos éstos entre 1910 y 1920.

En 1892 se instaló muy cerca del dique del pantano de Marismilla una construcción muy típica de toda la industria inglesa, que consistía en un edificio para bombear agua con bombas Cornish (Cornish Pump House), que actualmente no existe y tan sólo quedan los restos de los cimientos del mismo.

En todo esto tenemos que tener en cuenta que los diseños de los edificios industriales eran realizados en Inglaterra por ingenieros ingleses y comprobados en Riotinto por técnicos ingleses de la empresa.

En 1907 se construyó la fundición de Piritas, actualmente arrasados; poseía dos grandes chimeneas en la cumbre de un montículo (Sierra del Madroñal), con dos conjuntos de hormigón que, por encima de la falda del monte las enlazaba con la factoría. Junto a esta Fundición se construyó una fábrica de ácido sulfúrico, hoy también destruida.

Entre 1910 y 1920 se construyeron el almacén para lavadoras en Naya, el Laboratorio construido en 1919 con un conjunto de tres naves anexas al edificio de lavadoras y la Nueva Cochera de locomotoras de 1914, conservado actualmente como en su inicio y como taller de recuperación de parte del patrimonio ferroviario por la Fundación Riotinto.

\section{El cauce fluvial del río Tinto y su interés en Astrobiología}

\section{David Fernández Remolar \\ Centro de Astrobiologia. INTA - CSIC}

Las aguas del río Tinto fueron consideradas muertas durante años. El intenso color rojo de las aguas, su extrema acidez y la alta concentración en elementos metálicos evitaron dirigir esfuerzos en comprender el posible origen químico de este extraño sistema natural, los cuales fueron, por el contrario, utilizados para impulsar esfuerzos ambientales en la corrección quimica de sus aguas. Sin embargo, un grupo de investigadores y estudiantes de la Universidad Autónoma de Madrid, que iniciaron a finales de los ochenta el estudio de los posibles microorganismos que alli habitaran, descubrieron con sorpresa que el área fuente del río Tinto albergaba una comunidad de microbios muy diversa, resultado in-
3. P\&H Cerro Colorado

4. Locomotora Garrat

5. Grúa $15 \mathrm{Tn}$.

6. Central térmica Huerta Romana
Durante los años 1929 y 1930 se construyeron edificios de machaqueo y trituración de mineral para Naya y una nueva fábrica de ácido sulfúrico en lugar de la primitiva, edificio que fue abandonado después de la construcción de la nueva fábrica de ácido de Riotinto en 1960.

\section{B) Explotaciones mineras}

El yacimiento minero de Riotinto cuenta con una serie de masas minerales que permiten reunirlas en dos grandes grupos:

> Grupo Norte: compuesto por la masa Lago, Dehesa y Filón Norte o Salomón

$>$ Grupo Sur: formado por el Filón Sur o Nerva y la gran masa San Dionisio.

El criadero del Grupo Sur a efectos mineros está compuesto por filón Sur, San Dionisio y Masa Eduardo, aunque geológicamente se trata de un solo criadero con una longitud total de 3.000 metros.

La masa San Dionisio, a la cual pertenecen la Corta Atalaya y Pozo Alfredo, se localiza en el flanco sur del anticlinal de Riotinto, asociado a un pliegue menor (sinclinal) de dicho flanco. En este yacimiento concurren un Stockwork y un lentejón de sulfuros masivos situado sobre él. El Stockwork afecta a la roca del muro de los sulfuros masivos, que son fundamentalmente volcánicas ácidas altamente cloritizadas, lo que les confiere un color verdoso. Pues bien, la masa de sulfuros masivos se explotaba a cielo abierto mediante la Corta Atalaya y el Stockwork a través de Pozo Alfredo (minería subterránea).

En la actualidad, la Corta Atalaya es la seña de identidad de toda una comarca dedicada de por vida a la minería, como es la Cuenca Minera de Riotinto. Está situada al oeste del término mu- consistente con un ambiente supuestamente degradado. Estudios posteriores de la microbiología y química del agua en los noventa empezaron a evidenciar que gran parte de las condiciones de extrema acidez alcanzadas en el río eran originadas por la actividad de ciertos microoganismos -microbios quimiolitótrofos- que son capaces de sobrevivir oxidando los sulfuros metálicos, como la pirita, que conforman parte del basamento de la cuenca minera y que han sido fuente de su riqueza y del color característico del río.

Sin embargo, una prueba definitiva de la naturalidad del sistema extremo del río Tinto fue aportada mucho antes por un geólogo británico, J. Phillips, que en 1881 investigó los depósitos de óxidos de hierro o gossan situados en los alrededores de la localidad de Riotinto. Los estudios realizados por este científico permitieron conocer que los óxidos se formaron en ambientes lacustres con alto contenido en hierro. Teniendo en cuenta que los depósitos de hierro sedimentario se generaron en condiciones semejantes a las que hoy dia se observan en el río, y que su edad es mayor a la 

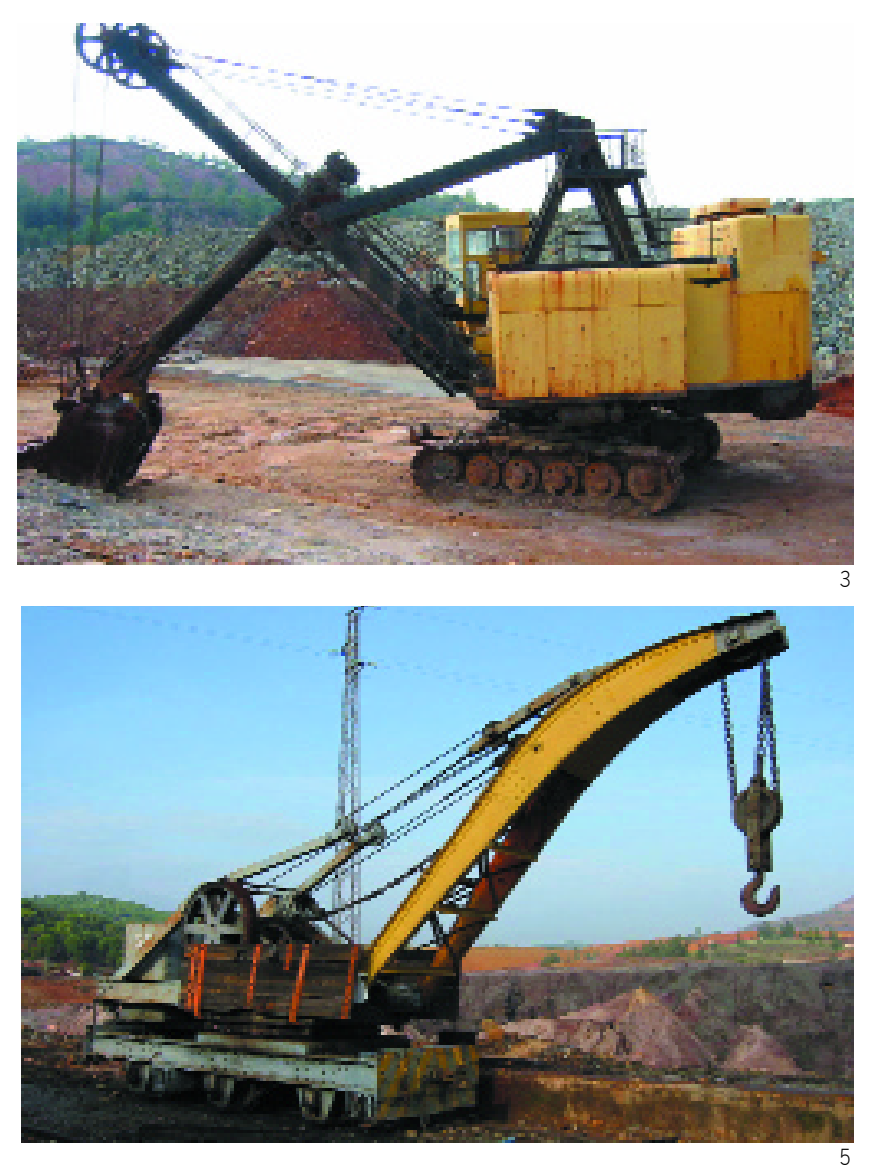

nicipal de Riotinto y su forma elíptica supone un inmenso y espectacular "cráter" cuyas dimensiones superan los 1.200 metros de diámetro en su parte más ancha por 900 en su parte más estrecha y 345 metros de profundidad, excavados sobre bancos de 12 metros de alto. Llegó a ser un modelo revolucionario de explotación minera que en tiempos albergó a más de 12.000 obreros en sus labores de arranque, carga y transporte de minerales. Es la mayor explotación a cielo abierto de Europa y quizás del mundo, llegando a explotar los sulfuros complejos de la serie Vulcanosedimentaria de la masa San Dionisio.

Esta explotación a cielo abierto, lo que los ingleses denominaban openn cast, comienza en 1907 con ayuda de las palas de vapor Bucyrus, en la masa de mineral denominada San Dionisio, pero
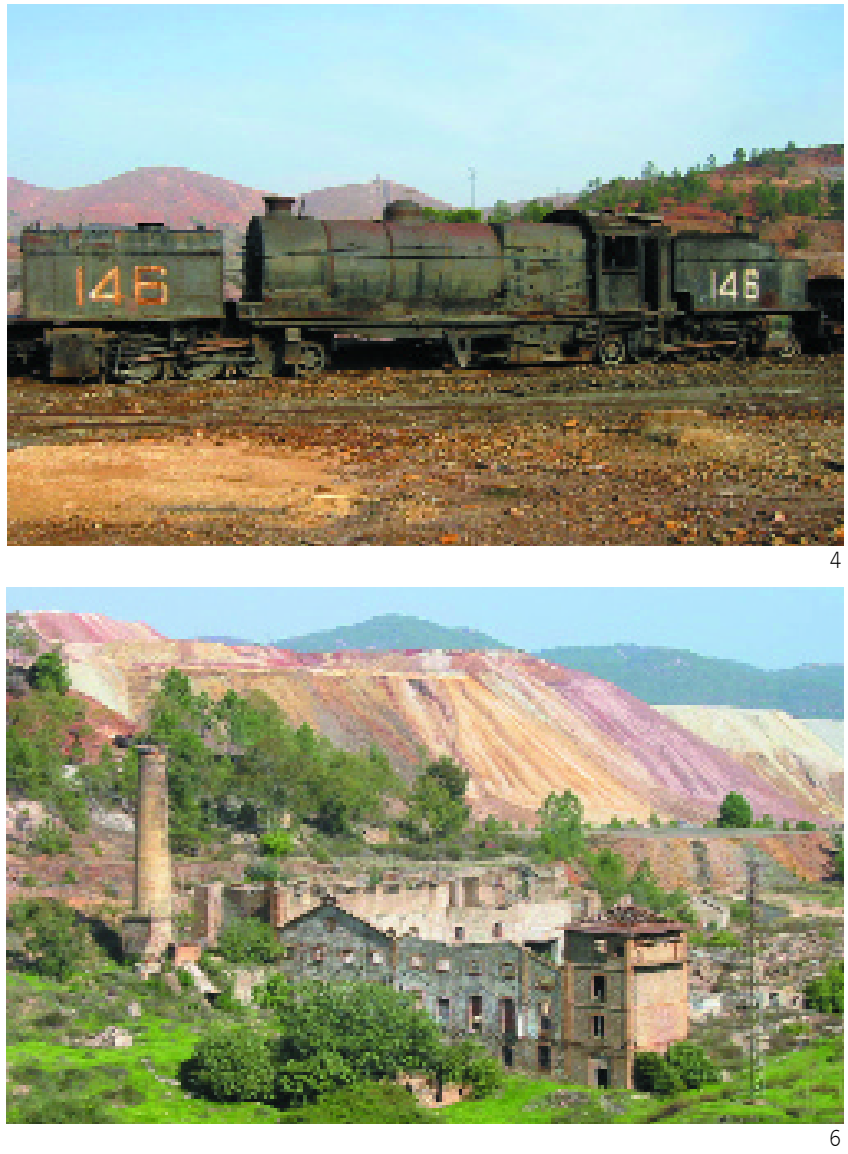

pronto se conocerá popularmente con el nombre de Corta Atalaya, gracias al pueblo que estaba al lado de los trabajos.

Entre 1912 y 1918 se construyó un túnel de más de 5 km. de longitud, que pasa por debajo del pueblo de Naya, atravesaba Filón Sur y conectaba con el piso 16 de Corta Atalaya, con la finalidad de transportar el mineral que se extraía desde la misma hasta Zarandas. Al principio se utilizaban máquinas de vapor pero en 1924 fueron sustituidas por las eléctricas.

En los años 60, las piritas explotadas por bancos se cargaban con palas eléctricas sobre vagones de 10 toneladas, los cuales eran arrastrados con locomotoras eléctricas por el túnel general del piso 16 hasta los depósitos de mineral. Las zafras arrancadas ocupación de la cuenca minera por la humanidad, se puede concluir que el sistema extremo del rio Tinto es un ambiente natural, si bien modificado recientemente por el hombre, que refleja la notable diversidad de hábitats del planeta en que vivimos.

Estas circunstacias han planteado la posibilidad de llevar a cabo estudios comparativos con Marte, un planeta en el que el hierro es ubicuo y ha tenido gran cantidad de agua superficial en diferentes momentos de su historia geológica. En este sentido, un grupo de científicos del Centro de Astrobiologia comenzó a buscar características geológicas comunes entre la cuenca del río Tinto y algunas regiones de Marte, que permitieran inferir la utilidad de este sistema terrestre para la exploración del planeta rojo. Lógicamente no se pueden generalizar condiciones ambientales de un área muy localizada en la Tierra respecto a Marte, cuyas condiciones atmosféricas globales actuales distan, además, mucho de las terrestres. En primer lugar, el planeta rojo no tiene agua disponible para mantener un sistema semejante al del rio Tinto en su superficie. En segundo lugar, un río no es un planeta y no debe ser utilizado para entender su dinámica global externa, la cual emerge de la interacción de una gran diversidad de ambientes superficiales.

Durante el estudio de algunas cuencas sedimentarias marcianas por científicos de la NASA, usando datos procedentes de la sonda Mars Global Surveyor que lleva orbitandoMarte hace 5 años, descubrieron en Sinus Meridiani (región ecuatorial de Marte) depósitos de óxidos de hierro cuyas caracteristicas mineralógicas parecian indicar un origen bajo una masa de agua líquida estable en tiempos primigenios. Este descubrimiento parecia conectar de forma directa al rio Tinto con una región concreta, aunque extensa, de Marte por medio de los productos sedimentarios de ambos sistemas planetarios: los óxidos de hierro.

La confirmación reciente de la existencia de agua en el subsuelo de Marte ha abierto nuevas expectativas sobre la posible existencia de 


\section{8 - 049 \\ Información del PH}

Informe BIC sobre la

Cuenca Minera de Riotinto

para su declaración como

Sitio Histórico

\section{PH45 - Octubre 2003}

por debajo del nivel 16 eran vaciadas mediante palas de empuje en los diferentes "pozos gloria" establecidos en el fondo de la corta, cayendo por gravedad hasta el piso 23, donde se cargan en vagones de cuatro toneladas que, formando trenes, son arrastrados por locomotoras eléctricas de troley hasta el pozo Roberto, para su elevación final a los depósitos de mineral establecidos en el piso 14

De Corta Atalaya se extraía pirita, para la fabricación de ácido sulfúrico y abonos, utilizados en la industria química. En Corta Atalaya se trabajó hasta los años 80 , cuando la crisis del precio del cobre hizo inviable su explotación.

La justificación de Corta Atalaya como elemento histórico de la minería onubense hay que buscarla desde antes de Cristo, pues ya hacia 2400 años A.C. se conocen datos de explotación en la zona.

La riqueza minero-metalúrgica es producto de un sustrato paleozoico formado por pizarras y grauvacas con sílice y cuarcitas asentado sobre un geosinclinal de origen volcánico que arrojó masas de azufre, hierro y cobre, así como oro y plata, y que dio lugar a la aparición de distintos distritos o provincias metalogenéticas, donde Riotinto fue la de mayor concentración de recursos mineros.

Su importancia también radica al ser un modelo revolucionario de explotación a cielo abierto, conocido más por el nombre de "cortas" y que se definen esencialmente como unas explotaciones tridimensionales (con importante profundidad) con un gran número de bancos descendentes. Su magnitud, su desarrollo y sus dificultades por tener que profundizar han convertido este método en el más avanzado técnicamente desde el punto de vista minero, como industrial, donde para las labores de arran- que y extracción se utilizan grandes maquinarias y voladuras para esos grandes movimientos de tierra que trajo aparejado una fuerte demanda de mano de obra, originando la inmigración de población procedente de diversos puntos de la península.

Es además una explotación donde tuvo lugar la revolución tecnológica acorde con los tiempos, dando lugar al empleo de multitud de sistemas de explotación y utilización de muchas variables en los elementos de extracción (material ferroviario, medios humanos, volquetes de grandes capacidades, palas cargadoras de grandes dimensiones, voladuras con grandes movimientos de tierra, etc.) y puesta a punto de nuevas técnicas de exploración y explotación.

El Filón Sur o Nerva alcanza una longitud de 1.350 metros en uno de sus niveles superiores y el afloramiento midió 1.700 metros, siendo su potencia media de unos 75 metros. Esta masa de pirita, hoy día agotada, se ha seguido explotando por los pórfidos cupríferos con destino a la concentración por flotación. La Masa Planes se considera también agotada, aunque quedan alli algunas piritas de extracción no remuneradora por leyes bajas.

El Grupo Norte, formado por las masas Dehesa, Lago y Salomón se alinea unos 600-800 metros por encima del grupo sur, o más concretamente al norte del Filón Sur. Las tres han sido explotadas y se consideran prácticamente agotadas como mina de piritas, si bien parece pueden extraerse aún alli grandes tonelajes de pórfidos cobrizos para flotación.

La masa Valle fue descubierta en 1867 por el ingeniero de minas Eloy Cossio y Cos, la cual tuvo escasas dimensiones, pero se estima que su situación representa un alto valor, como indicio de masas ocultas. vida reciente 0 actual en hábitats cripticos bajo la superficie. Seguir el agua liquida en otros planetas es, posiblemente, buscar vida extraterrestre en el sitio más favorable. Formas de vida quimiolitótrofas pueden habitar en el interior de planetas semejantes a la Tierra, ambientes que pueden llegar a ser muy estables durante millones de años, sin necesidad de recurrir a la luz solar para su supervivencia. Por ello, parte de la tecnología de exploración planetaria de Marte se está dirigiendo al desarrollo de instrumentación que sea capaz de encontrar agua y reconocer señales de posibles formas de vida que hayan podido sobrevivir en el subsuelo de Marte.

Como se ha indicado anteriormente, en el rio Tinto se han reconocido organismos que no requieren luz solar para su supervivencia, sino depósitos minerales de cuya oxidación obtienen energia. Teniendo en cuenta estos aspectos, el Instituto de Astrobiologia de la NASA (NAI) y el $C A B$ han focalizado sus esfuerzos en un proyecto de investigación Ilamado MARTE (Mars Analog Research And Technology Experiment) que llevará a cabo el sondeo del subsuelo del río Tinto para el des- arrollo de tecnología de exploración subterránea que sea capaz de detectar vida en los hábitats hídricos ocultos. Asimismo, diferentes laboratorios del CAB están involucrados en la construcción de vehículos de exploración superficial o instrumentos de análsis mineralógico o microbiológico que utilizan como banco de pruebas el ambiente extremo del río Tinto.

La importancia científica del río Tinto no se limita únicamente a su dimensión planetaria. La existencia de organismos que habitan condiciones extremas plantea interesantes interrogantes sobre los límites de la vida, los cuales sostienen los pilares del concepto mismo de vida. Conocer como estos organismos se han adaptado a las condiciones de extrema acidez, determinar su diversidad, inferir la antigüedad de las vías metabólicas utilizadas para su supervivencia o entender el papel jugado por estas comunidades en la biosfera naciente terrestre hace más de 3.000 millones de años son algunas de las importantes cuestiones que el rio Tinto puede ayudar a comprender. 

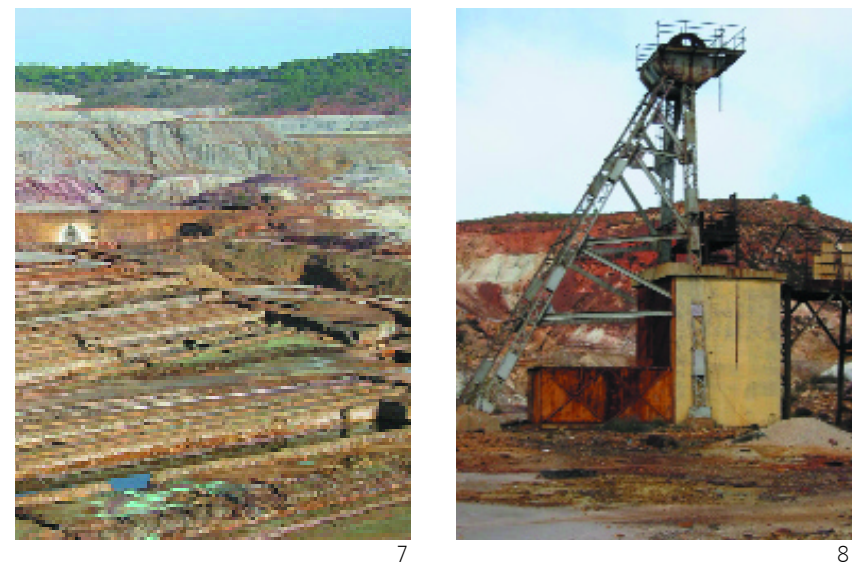

Siempre se ha considerado a Riotinto como una gran escuela de mineros. Lo fue hace decenas de años y lo ha sido hasta la actualidad. Los técnicos que aquí hayan trabajado pueden presumir, con justicia, de haber alcanzado una magnífica preparación en minería metálica. Son impresionantes los problemas que había y que hay que resolver en estas explotaciones, tanto de arranque, desagüe, ventilación, movimientos de minerales, embarques, etc., unidos a las dificultades propias de toda mina los inconvenientes del agua ácida, del gas sulfuroso, fuegos accidentales, zonas flojas de mineral casquero y, sobre todo, tener que extraer la mayoría de la pirita de una masa trabajada anteriormente y acribillada en todas direcciones por labores mineras abandonadas.

La mina Peña de Hierro está situada en el término municipal de Nerva y, más concretamente al sur de la sierra de San Cristóbal; debe su nombre al enorme crestón ferruginoso que corona la corta, el cual no se encuentra en la vertical de la masa piritica sino desplazado de la misma. Peña de Hierro estaba compuesta por un total de 36 concesiones mineras, que hacian 473,8111 hectáreas.

De todas estas instalaciones, hoy día tan sólo perduran algunas ruinas de la casa de máquinas del pozo maestro (el cual se encuentra tapado), el antiguo grupo Pilones y los lavaderos de pirita y azufrones. No obstante destaca la labor que se está llevando a cabo por la Fundación Riotinto en cuanto a la recuperación y restauración del túnel Sta. María que comunica con la corta para uso de la ruta turística, además de la recuperación del paisaje de alrededor desde el punto de vista histórico y minero.

\section{C) Material ferroviario}

Las minas de la provincia de Huelva se explotaron desde tiempos remotos, siendo las de Riotinto junto a las de Chipre probablemente las más antiguas del mundo. Las etapas tartésicas, fenicias y más tarde la romana fueron las de mayor esplendor para la minería onubense, bajando su nivel de explotación hacia el siglo XX.

A mediados de este siglo, todas las minas onubenses conocidas comienzan a caer en manos de empresas concesionarias extranjeras, principalmente inglesas y francesas. Pronto, todo el Andévalo onubense, comarca minera por excelencia, entra en ebullición, surgen ferrocarriles, muelles de embarque, explotaciones a cielo abierto, etc., dando lugar a una transformación económica y fisonómica de la provincia onubense.

En la compra de las minas de Riotinto por la empresa británica Riotinto Company Limited, se incluia a perpetuidad la propiedad del suelo y del subsuelo de todo el término municipal de Riotinto, así como la mayor parte de las casas del pueblo y todo lo re-
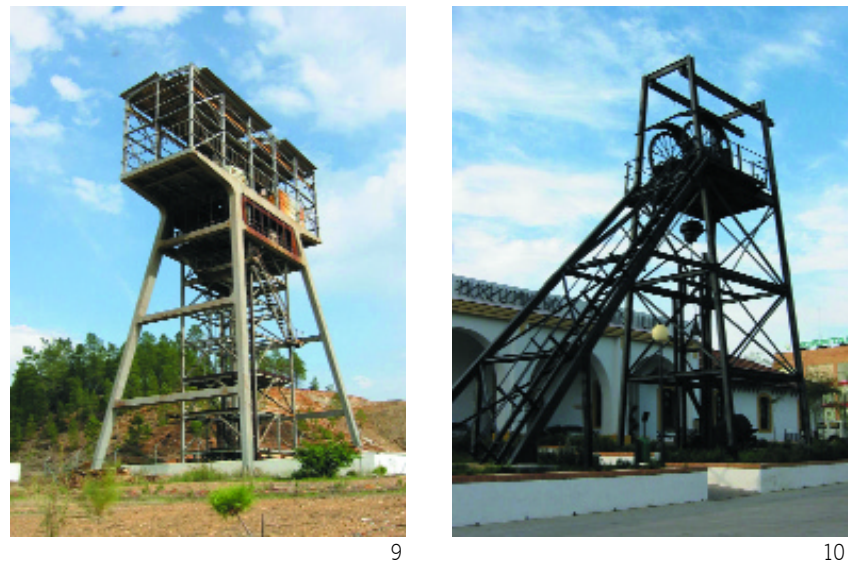

ferente a edificios y pertenencias de la explotación minera existente, así como la concesión de un ferrocarril que debía construirse entre las minas y el puerto de Huelva, según se exigía en una de las condiciones para la compra de las mismas.

Dos de las realizaciones más importantes de la compañia británica fueron sin duda el ferrocarril Riotinto-Huelva y la construcción del embarcadero de mineral en la ciudad de Huelva. Estas grandes infraestructuras permitieron la explotación masiva del mineral a cielo abierto, ya que se podian transportar al puerto de Huelva ingentes cantidades de mineral diariamente. Muy pronto el parque ferroviario de la empresa alcanzó niveles extraordinarios en cantidad y calidad, llegando en algún momento a poseer cerca de un centenar y medio de locomotoras en activo.

El proyecto del ferrocarril, puentes, túneles y muelle de la compañía inglesa fue encargado al ingeniero inglés George Barclays Bruce, comenzando las obras en julio de 1873. El ferrocarril de Riotinto-Huelva es de una anchura del tipo colonial inglesa, con 3 pies y 6 pulgadas $(1.067 \mathrm{~mm})$, teniendo una longitud de $84 \mathrm{ki}$ lómetros en la llamada vía general, pero además existían unos $270 \mathrm{~km}$. de vías repartidas en los ramales de Zalamea y Nerva, y radiando desde las estaciones de Riotinto y Naya con vías a los departamentos de Contramina, Cortas a cielo abierto, Fundición Piritas, Concentrador, Lavadora, Zarandas, Precipitación, Terreros Naya y Cerda, Talleres y los Almacenes de materiales y hulla.

La construcción del ferrocarril corrió a cargo de la empresa inglesa Clark and Punchard Co. Los primeros 13 kilómetros de trazado, Huelva-San Juan del Puerto discurren por las marismas de la orilla derecha del río Tinto, habiendo que terraplenar hasta unos 3 metros sobre el nivel del mar. El tramo San Juan del Puerto-Las Mallas (Niebla) de 14 kilómetros ofreció poca dificultad. Desde las Mallas hasta Riotinto el terreno pasa a ser abrupto y el ferrocarril se hace inseparable del río cruzándolo 4 veces mediante puentes metálicos y, en determinados momentos, perforando túneles.

Las obras terminaron en julio de 1875 y el presupuesto ascendió a 700.000 libras. Este ferrocarril, además de transportar las piritas entre Riotinto y Huelva y diversas mercancias, supuso un importante transporte de pasajeros en este trayecto, formándose trenes mixtos para este efecto. También de unas explotaciones a otras y en los ramales de Zalamea y Nerva se llegó a superar el millón de viajeros (la mayoría obreros). El objeto de la construcción de los ramales de Zalamea y Nerva fue proveer medios de transportes a los obreros que vivían en Nerva, El Valle, El Campillo y Zalamea la Real para acceder a los distintos departamentos de la Mina. Los precios de transporte eran muy bajos y la baja rentabilidad hizo que la empresa suspendiera este servicio de viajeros en 1968, sustituyéndolo por autobuses. 


\section{$050-051$ \\ Información del PH}

Informe BIC sobre la

Cuenca Minera de Riotinto

para su declaración como

Sitio Histórico

\section{PH45 - Octubre 2003}

El día 4 de abril de 1974 se cerraba la estación de Huelva remolcándose todo el carruaje que había con la locomotora $n^{\circ}$ 202. El día 9 de febrero de 1984 bajaba el último tren a Las MaIlas remolcado por la locomotora diesel n 911. La misma máquina remolcaría las tres locomotoras eléctricas $n^{0} 1,4$ y 6 que se encontraban en Las Mallas y el día 24 se retiraban los 43 vagones vacios del tren que bajó el día 9. Con este último servicio quedaba clausurado definitivamente el ferrocarril.

En lo concerniente al material motor de la compañia, Ilegó a tener 150 locomotoras de vapor, 5 diesel, 15 eléctricas y 2 de aire comprimido. Se compraron todas nuevas, la mayoría británicas, predominando las locomotoras escocesas, recurriendo además a fábricas alemanas y españolas.

En 1890 se contaba con 30 locomotoras de ancho $1067 \mathrm{~mm}$. y 4 para el ancho $600 \mathrm{~mm}$. En 1930 estaba casi completa la totalidad de locomotoras con 143 de vapor y 4 eléctricas, aunque algunas fueron desguazadas o estaban fuera de servicio. Entre los años 1953-54 se compraron 6 nuevas máquinas de vapor para sustituir a las fatigadas Garrat adquiridas en 1929, y en 1960 se adquiere la primera locomotora diesel-hidráulica, 6 años más tarde una serie de 4 diesel-eléctricas de fabricación española. Por último en la década de los 70 se completa con 2 tractores diesel-hidráulica para maniobras y 2 locomotoras diesel-eléctricas para la vía general fabricadas en España.

El verdadero impulso del ferrocarril de Riotinto se produce cuando Ilega George Rice Trevor Lewis en 1931 sustituyendo a Mr. Harding. George Rice (Don Jorge), que estuvo en Riotinto hasta su jubilación en 1959, fue un verdadero experto en ferrocarriles. Llevó a cabo una fuerte reforma en la vía general, bajando la rasante en los túneles para ganar gálibo a las locomotoras de la clase 200. Reforzó los puentes para el paso de las grandes Garrats y mandó pintar el flanco de las locomotoras con grandes y característicos números blancos, para distinguirlas de lejos.

Aunque numeró todas sus locomotoras, Don Jorge propuso la clasificación dentro de una serie de grandes grupos diferenciados por las letras del alfabeto, que fueron desde la $A$ hasta la 0 y otras sueltas que fueron designadas por números. Todas las locomotoras estuvieron siempre pintadas de negro y la traviesa de toperas con un ribete rojo. En las fotos de fábrica se observan los tenders fileteados con líneas de distinto grosor, las placas del fabricante colocadas a cada lado de los tanques y el número que le asignó Rio Tinto Company, situado a cada lado de la chimenea de latón. Hasta los años cuarenta algunas de la clase I lucian sus domos pulimentados en latón.

En el año 1946 estaban inventariadas 104 locomotoras, de las cuales 55 estaban en reparación, lo que da una idea de la importancia del ferrocarril en la comarca minera de Riotinto. El ferrocarril de Riotinto nació a consecuencia de solventar el problema de transporte de mineral fuera de nuestro país. Esto se llevó a cabo a partir de la construcción del muelle cargadero en el puerto de Huelva, construcción llevada a cabo por el ingeniero inglés George Barclay Bruce.

La construcción y ubicación del muelle embarcadero estuvo apoyada en los anteriores trabajos de Deligny entre 1853 y 1859 , donde sus sondeos en la ría del Odiel encontró calados de dieciocho pies en marea baja y veintidós en marea alta y su posterior comprobación de la posibilidad de entrada de barcos de mil toneladas. Pero ante esto no debemos olvidar que el 29 de marzo de 1873 , fecha de constitución de la compañía, ya existía el ferrocarril de Tharsis a Huelva y su muelle, y por supuesto el anteriormente construido del Buitrón a San Juan del Puerto, por lo que Huelva era ya un importante puerto de salida de minerales y más aún cuando se instaló la RTCL.

\section{Bibliografía}

AGUILERA COLLADO, E. (1998) Arqueología Industrial. Zarandas en Minas de Riotinto. En J.A. MÁRQUEZ (dir.) Artes, costumbres y riquezas de la provincia de Huelva. Madrid, 1998, pp. 793-808

ESCALERA REYES, J. y VALCUENDE DEL RÍo, J.M. (1994) Patrimonio industrial-patrimonio etnológico: El caso de la Cuenca Minera de Riotinto. En II Jornadas Ibéricas do Patrimonio Industrial. Lisboa, 1994

FUNDACIÓN Riotinto (1994). La Comarca Minera de Riotinto. Un Territorio de Mina. Sevilla, 1994

GONZÁLEZ VILCHES, M. (1981) Historia de la arquitectura inglesa en Huelva. Universidad de Sevilla/Diputación Provincial de Huelva. Sevilla, 1981

HARVEY, C.E. (1981) The Rio Tinto Company. An economic history of a leading international mining concern, 1873-1954. Penzance, Londres, 1981

PINEDO VARA, I. (1963) Piritas de Huelva. Madrid, Summa, 1963

RUIZ BALLESTEROS, E y DELGADO RAMOS, J.M. (1996) La Esquila de Riotinto. En P. CANTERO (coord.) Demófilo n 19. Huelva: Palabra, Rituales y Fiestas. Fundación Machado-Diputación Huelva, 1996

RUIZ BALLESTEROS, E. (1999) Intervenciones sobre el patrimonio minero en Riotinto. En J. AGUDO y E. FERNÁNDEZ DE PAZ (coord.) Patrimonio cultural y museología. Actas del VIII Congreso de Antropología, Santiago de Compostela, 1999, pp. 111-118

VV.AA. (1990) Futuro de la minería onubense. Dirección General de Industria, Energía y Minas, Junta de Andalucía. Sevilla, 1990 